\title{
ISOTHERMAL AND THERMODYNAMICAL MODELING OF CHROMIUM (III) ADSORPTION BY COMPOSITES OF POLYANILINE WITH RICE HUSK AND SAW DUST
}

\author{
FARAH KANWAL, RABIA REHMAN*, TARIQ MAHMUD, JAMIL ANWAR, RABIA ILYAS
}

Institute of Chemistry, University of the Punjab, Lahore-54590, Pakistan

(Received: September 15, 2011 - Accepted: December 16, 2011)

\begin{abstract}
The adsorption of $\mathrm{Cr}$ (III) from water by polyaniline composites with rice husk and saw dust of Eucalyptus camaldulensis has been investigated in this study. The surface of adsorbents was characterized by FT-IR. Effect of various operational conditions like agitation time, initial pH, adsorbent dose, particle size of composites and temperature were studied in batch mode. The suitability of the data was confirmed by Langmuir and Freundlich isotherms. Thermodynamic studies showed that adsorption of $\mathrm{Cr}$ (III) on these composites occur spontaneously. Rice husk and saw dust modified the morphology of polyaniline by preventing its aggregation and improving its adsorption capacity.
\end{abstract}

Keywords: Polyaniline, composite, chromium (III), adsorption, isotherms.

\section{INTRODUCTION}

The occurrence of heavy metal ions in water is a pervasive environmental issue at the moment. Chromium is considered as one of the top sixteen toxic pollutants. Chromium exists in environment both in trivalent and hexavalent forms of which hexavalent form is 500 times more toxic than the trivalent one. ${ }^{1}$ Toxicity of chromium to human beings includes, skin irritation to lung cancer, as well as kidney, liver, and gastric damage. It has become a serious health concern because of its carcinogenic and teratogenic effects on organisms. ${ }^{2}$ Chromium enters into the environment through various manufacturing units like paint industry, iron and steel industries, metal finishing industry and inorganic chemicals production units. Extensive use of chromium compounds results in large quantities of chromium containing effluents which need a scrupulous instant treatment before their discharge into water streams. WHO (World Health Organization, 1993) recommended guideline value for chromium (as total chromium) in drinking water as $0.05 \mathrm{mg} / \mathrm{L}$ (desirable) and the permissible limit of chromium for drinking water is $0.1 \mathrm{mg} / \mathrm{L}$ (as total chromium) in EPA standard, hence the removal of $\mathrm{Cr}$ (III) from wastewater is important before discharging them into main water streams of our ecosystem. ${ }^{3,4}$

Various methodologies have been adopted to remove $\mathrm{Cr}$ (III) from waste water. They include chemical precipitation, membrane process, ion exchange, liquid extraction and electrodialysis. All of these physical and chemical methods of treatment have many disadvantages such as incomplete metal removal, high reagent and energy requirements, high capital investment and running costs, generation of toxic sludge or other waste products that require further disposal or treatment. Effective and eco-friendly treatment is thus needed to be developed for reducing heavy metal contents. ${ }^{5,6}$

Adsorption is an effective and versatile method for removal of heavy metals when combined with appropriate desorption and metal recovery step solving the problem of sludge disposal. ${ }^{7-9}$ It is a well known fact that nitrogen atom in compounds of amine derivative forms co-ordinate bond with positive charge of metals due to the presence of electron in $s p^{3}$ orbital of nitrogen. So, these types of materials having nitrogen donor atom are generally explored as adsorbents. ${ }^{10,11}$ The present laboratory-scale study aims at investigating the feasibility of polyaniline, a polymer with terminal amine $\left(-\mathrm{NH}_{2}\right)$ group for removal of $\mathrm{Cr}$ (III) form waste water. Bare polyaniline particles are mostly aggregated in solution, which results in lowering of adsorption capacity and slow kinetics. If this aggregation of polyaniline could be properly and directly controlled, the adsorption capacity could be enhanced amazingly. So in site polymerization of aniline onto the surface of other materials is adopted for controlling aggregation. ${ }^{12}$

Polyaniline is one of the leading and widely used conducting polymers. Its general molecular structure is shown in Fig. 1.

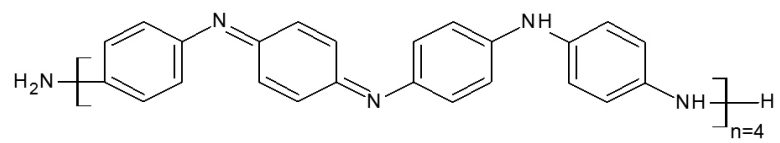

Fig.1: General molecular structure of polyaniline.
It is synthesized by using various methods chemically/electrochemically in the shape of powder or film. It is employed in many progressive applications, like rechargeable batteries, charge storage devices, protector shield in magnetic fields, sensors, biosensors, catalytic processes, microwave absorption, image processing and infrared optic applications because of its good combination of properties like low cost, ease of synthesis and environmental stability. ${ }^{13}$ Polyaniline has also shown good potential for adsorbing heavy metals from the effluents. It contains a lot of imine and amine groups, which can chelate cationic metal ions as well as adsorb anionic metal species via electrostatic interactions or through hydrogen bonding. Therefore, it can be employed as base material for removal of heavy metals from wastewater. For example, adsorption of toxic hexavalent chromium in water was successfully carried out by this compound in powdered form. ${ }^{14-16}$

The main concern of this work was to synthesize, characterize and compare the adsorption properties of the polyaniline/rice husk and polyaniline/ saw dust composites for removal of chromium (III) from water as compared to simple polyaniline in batch mode. The parameters studied include; particle size of adsorbent, influence of initial $\mathrm{pH}$, dose of adsorbent, contact time interval, agitation rate and temperature. The adsorption isotherms and thermodynamics were investigated for determining the possible mechanism. Regeneration of adsorbents by various eluents was carried out. Optimized conditions of adsorption were applied for real industrial waste water effluents.

\section{Experimental Work}

\section{Materials and Methods}

Balance ER-120A (AND), Electric grinder (Ken Wood), pH meter (HANNA pH 211) and flame atomic absorption spectrophotometer (Perkin Elmer AAnalyst 100) using air-acetylene flame were used. All chemicals used during this research work of Anala $\mathrm{R}$ grade and were used as such. $\mathrm{NaCl}$, Aniline, $\mathrm{K}_{2} \mathrm{Cr}_{2} \mathrm{O}_{7}, \mathrm{HCl}, \mathrm{NaOH}, \mathrm{CrCl}_{3} \cdot 6 \mathrm{H}_{2} \mathrm{O}$. Deionized water was used for the preparation of all types of solutions and dilutions where ever required. Rice husk and saw dust of Eucalyptus camaldulensis were purchased from local market and ground to 60 ASTM particle size. BET surface area of all synthesized adsorbents was determined using "ASAP 2000 (Micromeritics)" using nitrogen as adsorbate at $77 \mathrm{~K}$. Stock solution of $1000 \mathrm{ppm}$ of $\mathrm{Cr}$ (III) was prepared by dissolving $5.125 \mathrm{~g}$ of chromium chloride per liter of deionized water. Standard solutions of $\mathrm{Cr}$ (III) were prepared by successive dilution of this Stock solution.

\section{Preparation of adsorbents}

For preparing the polyaniline/rice husk (PANI/R.H) composite, $10.0 \mathrm{~mL}$ aniline was mixed with $100.0 \mathrm{~mL}$ of $\mathrm{HCl}\left(2.0 \mathrm{~mol} \mathrm{~L}^{-1}\right)$ with constant stirring. This mixture was placed in a freezing mixture of ice and $\mathrm{NaCl}$ in an ice bath, followed by the addition of $0.1 \mathrm{~mol} \mathrm{~L}^{-1} \mathrm{~K}_{2} \mathrm{Cr}_{2} \mathrm{O}_{7}$ dropwise. $2.0 \mathrm{~g}$ powdered rice husk was also added in it along with $\mathrm{K}_{2} \mathrm{Cr}_{2} \mathrm{O}_{7}$ slowly. The mixture was stirred continuously for three hours. Its color turned dark green, indicating polymerization of aniline. This mixture was placed in refrigerator at $-10.0^{\circ} \mathrm{C}$ for 24 hours for the complete precipitation of composites. These precipitates of composites were separated then by filtration and washed with acetone and $2.0 \mathrm{~mol} \mathrm{~L}^{-1} \mathrm{HCl}$ for removing excess of residual monomer and other impurities. They were dried at $50{ }^{\circ} \mathrm{C}$ for 48 hours in an oven. Polyaniline (PANI) was 
synthesized in the same way without rice husk addition. Polyaniline/saw dust (PANI/S.D) composite was synthesized by the adopting the same procedure and replacing rice husk with powdered saw dust of Eucalyptus camaldulensis. All the adsorbents were stored in colored glass bottles and used for further adsorption experiments. ${ }^{17}$

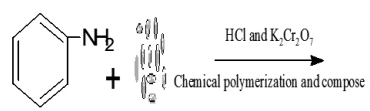

Aniline Rice husk/Saw dust

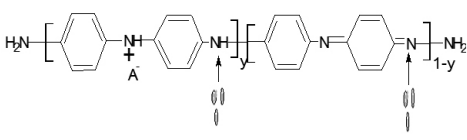

Polyaniline composite
Fig. 2: Preparation of composites

\section{FT-IR Characterization}

The first step was the characterization of adsorbents surface to confirm the presence of groups like $-\mathrm{OH},-\mathrm{CN},-\mathrm{NH}$, and $-\mathrm{C}=\mathrm{C}$ - that can act as possible active sites for $\mathrm{Cr}$ (III) adsorption and to check the structural changes occurred due to composite formation in polyaniline. For this purpose, the adsorbents were characterized by recording their FT-IR spectra using FT-IR spectrophotometer (Perkin Elmer-RXI) in the range of $4000-700 \mathrm{~cm}^{-1}$. The resulting characteristic vibration frequencies are presented in Table $1 .{ }^{17}$

\section{Adsorption Experiments}

The adsorption studies were carried out at $25 \pm 1{ }^{\circ} \mathrm{C}$. $\mathrm{pH}$ of the solution was adjusted to different values according to the requirement, with $0.1 \mathrm{M} \mathrm{HCl}$ and $0.1 \mathrm{M} \mathrm{NaOH}$. A known amount of different adsorbents (i.e. PANI, PANI/ R.H and PANI/S.D) was added to Cr (III) samples separately and allowed sufficient time for adsorption equilibrium. The effects of various parameters on the rate of adsorption process were investigated by varying contact time, (10$60 \mathrm{~min}$ ), adsorbent amount $(0.5-2.5 \mathrm{~g})$, initial $\mathrm{pH}$ of the solution (1-7), agitation speed $(50-300 \mathrm{rpm})$ and temperature $\left(10-80{ }^{\circ} \mathrm{C}\right)$. The solution volume was kept constant i.e. $50 \mathrm{~mL}$. After attaining the adsorption equilibrium, all these mixtures were filtered off with sintered glass crucible. Filtrates were analyzed for chromium by flame atomic absorption spectrophotometer working at resonance wavelength $357.9 \mathrm{~nm}$. The \% age removal of metal ions in terms of adsorption was determined by the following equation-1:

$$
\% \text { age Removal of Metal ions }=\frac{\mathrm{C}_{\mathrm{o}}-\mathrm{C}_{\mathrm{e}}}{\mathrm{C}_{\mathrm{o}}} \times 10 \mathrm{C}
$$

Where $\mathrm{C}_{\mathrm{o}}$ and $\mathrm{C}_{\mathrm{e}}$ are the concentrations of $\mathrm{Cr}$ (III) before and after adsorption process respectively. In all batch experiments, average values were taken from triplicate measurements with the experimental error in the range of $0.5-2.0 \%{ }^{5,8,15}$

\section{Study of adsorption isotherms}

$50 \mathrm{~mL}$ of six solutions with concentrations $30,40,50,60,70$ and $80 \mathrm{ppm}$ were prepared by proper dilution of stock solution of $\mathrm{Cr}$ (III). The optimum conditions of $\mathrm{pH}$, adsorbent dose, adsorbent particle size, agitation speed, temperature and contact time were adopted according to the sample of adsorbent used for studying adsorption isotherm. At the end, suspensions were filtered off and the filtrates were analyzed for remaining $\mathrm{Cr}$ (III) concentration by using flame atomic absorption spectrophotometer. Langmuir isotherm was plotted by using its standard straight-line equation-2:

$$
\frac{1}{q}=\frac{1}{b q_{m} C_{e}}+\frac{1}{q_{m}}
$$

The value of $\mathrm{q}$ is calculated by using this formula (Eq.3):

$$
\mathrm{q}=\frac{\left(C_{o}-C_{e}\right) V}{m}
$$

Where ' $\mathrm{q}$ ' $\left(\mathrm{mg} \mathrm{g}^{-1}\right)$ is the amount of $\mathrm{Cr}$ (III) adsorbed, ' $\mathrm{C}_{\mathrm{e}}$ ' (ppm) is the concentration of $\mathrm{Cr}$ (III) at equilibrium, ' $\mathrm{q}_{\mathrm{m}}$ ' $\left(\mathrm{mg} \mathrm{g}^{-1}\right)$ and $\mathrm{b}\left(\mathrm{Lg} \mathrm{g}^{-1}\right)$ are Langmuir isotherm parameters which were calculated from the slope and intercept values of the linear plot of ' $1 / \mathrm{q}$ ' versus ' $1 / \mathrm{C}_{\mathrm{e}}$ '. Whereas ' $\mathrm{V}$ ' is the volume of $\mathrm{Cr}$ (III) solution in liters and ' $\mathrm{m}$ ' is the mass of adsorbent used. Freundlich isotherm was plotted using following standard straight-line equation-4:

$$
\log \mathrm{q}=\log K_{F}+\frac{1}{n} \log C_{e} \quad \text { (Eq.4) }
$$

The value of ' $\mathrm{K}_{\mathrm{F}}$ ' can be determined from intercept and ' $1 / \mathrm{n}$ ' can be determined from the slope of the linear plot of ' $\log \mathrm{q}$ ' versus ' $\log \mathrm{C}_{\mathrm{e}}$ '. ' $\mathrm{K}_{\mathrm{F}}$ ' and ' $1 / \mathrm{n}$ ' are Freundlich isotherm parameters. ${ }^{5,8}$

Sorption thermodynamic

Gibbs free energy change $\left(\Delta \mathrm{G}^{o}\right)$ is a thermodynamic parameter which is the fundamental criterion of spontaneity of adsorption process. The process of adsorption occurs spontaneously at a given temperature if $\Delta \mathrm{G}^{o}$ is a negative quantity. Its value was calculated using relationship given in equation-5

$$
\Delta G^{o}=-R T \ln (K)
$$

Where $\Delta \mathrm{G}^{o}$ is the free energy change in $\mathrm{KJ} / \mathrm{mol}$, $\mathrm{T}$ is the absolute temperature in Kelvin, $\mathrm{R}$ is the universal gas constant with the value 8.314 $\mathrm{J} . \mathrm{mol} / \mathrm{Kelvin}$ and $\mathrm{K}$ is the reciprocal of Langmuir constant ' $\mathrm{b}$ '. ${ }^{18}$

Regeneration of adsorbents

For finding a better eluent for desorption of $\mathrm{Cr}$ (III) form adsorbents for their reusability, various acids were tried. The used adsorbents were regenerated using $50 \mathrm{~mL}$ of $10.0 \mathrm{mmol} \mathrm{L}^{-1}$ solution of $\mathrm{HCl}, \mathrm{HNO}_{3}$ and $\mathrm{CH}_{3} \mathrm{COOH}$ separately in $250 \mathrm{~mL}$ Erlenmeyer flasks, while stirring at $100 \mathrm{rpm}$ for $30 \mathrm{~min}$ at room temperature. After that, regenerated adsorbents were dried in an oven at $60^{\circ} \mathrm{C}$ for 2-3 $\mathrm{h}$ and then reused. The eluted Cr (III) per gram of adsorbent $\left(\mathrm{q}_{\text {des }}\right)$ from the concentration of $\mathrm{Cr}$ (III) desorbed $\left(\mathrm{C}_{\mathrm{des}}\right)$ in the solution was calculated by following relationship:

$$
\mathrm{q}_{\text {des }}=C_{\text {des }} \frac{V}{m}
$$

Where ' $\mathrm{V}$ ' is the volume of the eluent used in Liters and ' $\mathrm{m}$ ' is weight of the adsorbent in grams. \% age desorption was calculated by comparing $\mathrm{Cr}$ (III) desorbed $\left(\mathrm{q}_{\text {des }}\right)$ to the $\mathrm{Cr}(\mathrm{III})$ adsorbed $(\mathrm{q})$ using this equation: ${ }^{15}$

$$
\% \text { age Desorption }=\frac{\mathrm{q}_{\text {des }}}{\mathrm{q}} \times 100 \quad(\text { Eq.7) }
$$

\section{RESULTS AND DISCUSSION}

\section{Characterization of adsorbents}

FT-IR spectra of polyaniline and its composites confirm the presence of a particular band found in the $1100-1140 \mathrm{~cm}^{-1}$ region. This is the characteristic band for conductive polyaniline and it is due to charge delocalization on the polymer backbone. The intensity of peak is the measure of conductivity and the delocalization of electrons. These observations suggested that there is no structural difference between isolated polyaniline and polyaniline in the composites. The characteristic peaks due to $\mathrm{N}-\mathrm{H}$ stretching at 3400 and 3425 $\mathrm{cm}^{-1}$ in polyaniline and its composites were observed at 3401,3406 and 3400 $\mathrm{cm}^{-1}$. The peaks due to the aromatic C-H stretching are found at 2904, 2908 and 2902 in PANI, PANI/R.H and PANI/S.D respectively.

The band in the region of $1472-1586 \mathrm{~cm}^{-1}$ is indicative of the nitrogen bonded benzene (B), quinoid (Q) rings. The bands observed at 1574, 1589 and $1590 \mathrm{~cm}^{-1}$ in PANI, PANI/R.H and PANI/S.D correspondingly, are due to the stretching of $\mathrm{N}=\mathrm{Q}=\mathrm{N}$ group, whereas the bands observed at 1492, 1511 and $1497 \mathrm{~cm}^{-1}$ in polyaniline and its composites are due to the stretching of $\mathrm{N}=\mathrm{B}=\mathrm{N}$ group. In composites, these groups' vibrational frequencies show a shift towards higher wave number as compared to isolated polyaniline value which indicated the presence of physiochemical bonding between polyaniline and rice husk/saw dust. ${ }^{18}$ The surface areas of PANI and its composites are recorded in Table 2. It was found that modification of polyaniline with rice husk and saw dust had caused the surface area of the polyaniline to significantly increase, i.e., from 35.7 to 38.7 and $41.3 \mathrm{~m}^{2} \mathrm{~g}^{-1}$ respectively. The pore size in PANI/S.D was larger in these adsorbents. The pores are large enough to allow the penetration of $\mathrm{Cr}$ (III) metal ions. 
Table 1: Characteristic FT-IR band absorption frequencies of adsorbents.

\begin{tabular}{|c|c|c|c|c|}
\hline Vibrational Assignment & $\begin{array}{c}\text { Polyaniline } \\
\left(\mathbf{c m}^{-1}\right)\end{array}$ & $\begin{array}{c}\text { Polyaniline/rice husk } \\
\text { composite } \\
\left(\mathbf{c m}^{-1}\right)\end{array}$ & $\begin{array}{c}\text { Polyaniline/saw dust } \\
\text { composite } \\
\left(\mathbf{c m}^{-1}\right)\end{array}$ & $\begin{array}{c}\text { Reference Absorption frequency } \\
\text { ranges } \\
\left(\mathbf{c m}^{-1}\right)\end{array}$ \\
\hline N-H stretching & 3401 & 3406 & 2400 & 3426 \\
\hline Aromatic C-H stretching & 2904 & 2908 & 1652 & 1713 \\
\hline C-NH stretching & 1683 & 1692 & 1590 & 1577 \\
\hline N=Q=N & 1574 & 1589 & 1497 & 1295 \\
\hline N=B=N & 1492 & 1511 & 1292 & 1238 \\
\hline C-N stretching & 1290 & 1295 & 1245 & 1030 \\
\hline C=N stretching & 1240 & 1246 & 1109 & 830 \\
\hline Aromatic C-N-C & 1121 & 1139 & 1040 & 744 \\
\hline C-H in plane & 1036 & 1037 & 799 & \\
\hline C-H out of plane & 795 & 812 & 755 & \\
\hline Phenazine like ring by cyclization & 750 & 753 & 681 & \\
\hline C-Cl stretching & 682 & 697 & & \\
\hline
\end{tabular}

Table 2: Characterization of adsorbents by BET data.

\begin{tabular}{|c|c|c|c|}
\hline Characteristics & PANI & PANI/R.H & PANI/S.D \\
\hline BET surface area $\left(\mathrm{m}^{2} \mathrm{~g}^{-1}\right)$ & 35.7 & 38.7 & 41.3 \\
\hline Average pore diameter $(\mathrm{nm})$ & 1022.6 & 32064.5 & 46892.9 \\
\hline $\begin{array}{c}\text { Mesopore volume of pores }\left(\mathrm{V}_{\text {meso }}\right) \\
\left(\mathrm{cm}^{3} \mathrm{~g}^{-1}\right)\end{array}$ & 0.06 & 2.46 & 3.82 \\
\hline Total acidic groups $\left(\mathrm{mmol} \mathrm{g}^{-1}\right)$ & 0.83 & 1.29 & 2.21 \\
\hline Total basic groups $\left(\mathrm{mmol} \mathrm{g}^{-1}\right)$ & 2.31 & 4.52 & 5.31 \\
\hline
\end{tabular}

\section{Effect of particle size}

To observe the effect of particle size of adsorbents on the rate of adsorption, different mesh sized polyaniline (PANI), polyaniline/rice husk (PANI/R.H) and polyaniline/saw dust (PANI/S.D) composites were used for adsorption. The results are shown in Fig. 3.

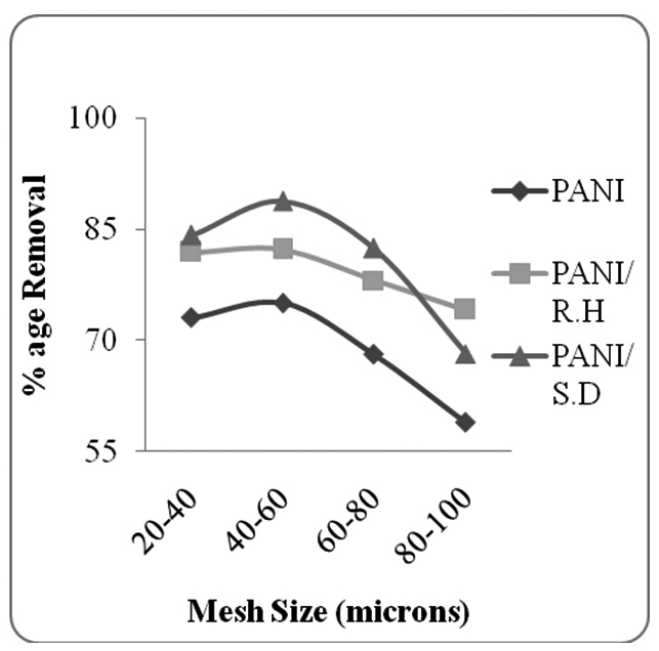

Fig. 3: Effect of particle size on \% age removal of Cr (III).

Maximum \% age removal of $\mathrm{Cr}$ (III) was observed by polyaniline/saw dust (PANI/S.D) composite of mesh sized 40-60 microns. It was found that adsorption rate decreased with the increase in mesh size of adsorbents. The particle size decreases with increasing mesh size and surface area exposed for adsorption of $\mathrm{Cr}$ (III) increases. This is due to the increase in accessibility of adsorbate to the pores of the adsorbents with the decrease in particle size. But very small particles start aggregating and coagulating, resulting in decrease of adsorption. ${ }^{5,8,15}$

Effect of adsorbent dose

The effect of variation in the adsorbent dose on the \% age removal of $\mathrm{Cr}$
(III) was studied. The results are presented in Fig. 4. It was observed that the $\%$ age removal of $\mathrm{Cr}$ (III) was increased with increasing adsorbent dose. The maximum $\%$ age removal values were obtained when the adsorbent dose was $1.5 \mathrm{~g}$ using polyaniline (PANI), whereas $1.0 \mathrm{~g}$ employing polyaniline/rice husk (PANI/R.H) and polyaniline/saw dust (PANI/S.D) composites.

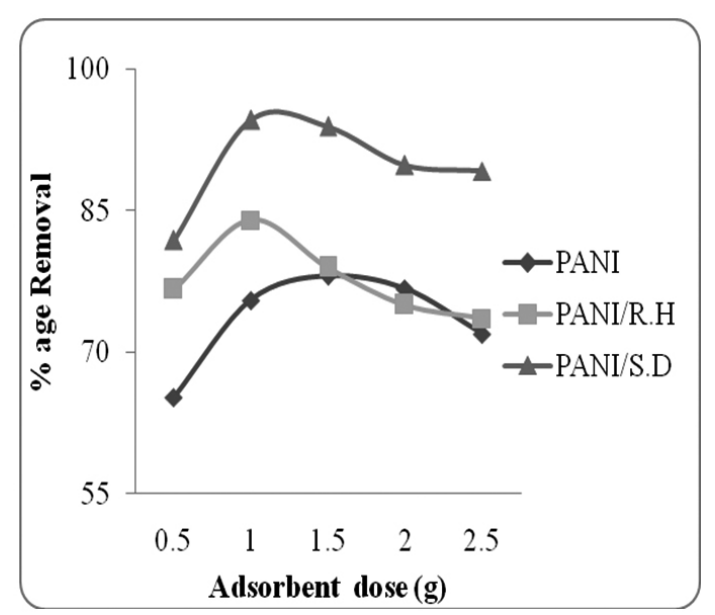

Fig. 4: Effect of adsorbent dose on \% age removal of Cr (III).

This increase in adsorption with small adsorbent does in case of polyaniline/ saw dust (PANI/S.D) composites was due to the availability of more adsorption sites. The maximum \% age removal of $\mathrm{Cr}$ (III) using polyaniline/saw dust (PANI/S.D) composite was $94.6 \%$. In case of polyaniline/rice husk (PANI/ R.H) composite, the maximum $\%$ age removal of $\mathrm{Cr}$ (III) was $84 \%$, whereas it was $78.09 \%$ using isolated polyaniline (PANI). These results depicted that the saw dust composite with polyaniline enhanced its efficiency to remove $\mathrm{Cr}$ (III) by preventing its particles from aggregation and exposing more vacant sites for adsorption. ${ }^{5,8}$

Effect of contact time

The phenomenon of adsorption is a time dependent process. The effect of various time intervals on the $\%$ age removal of $\mathrm{Cr}$ (III) by Polyaniline and its composites was studied. The results are presented in Fig. 5. The maximum \% age removal values were obtained when the contact time was 20 minutes in case of polyaniline/saw dust (PANI/S.D) composite, while 30 minutes using polyaniline (PANI) and polyaniline/rice husk (PANI/R.H) composite. 


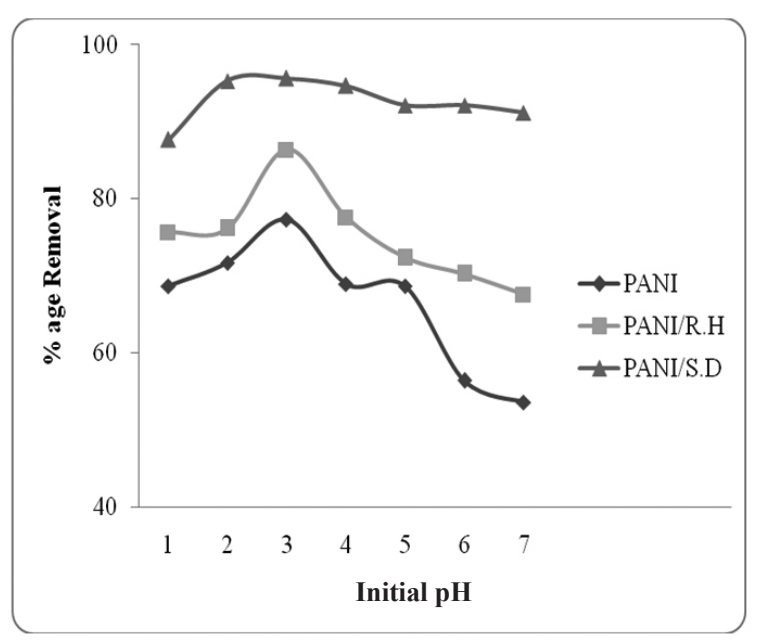

Fig. 5: Effect of contact time on \% age removal of $\mathrm{Cr}$ (III).

The reduced time interval for maximum removal of $\mathrm{Cr}$ (III) using polyaniline/saw dust (PANI/S.D) composite revealed that it has more adsorption sites which are available for rapid uptake of metal ions. The maximum $\%$ age removal of $\mathrm{Cr}$ (III) using polyaniline/saw dust (PANI/S.D) composite was $93.08 \%$. In case of polyaniline/rice husk (PANI/R.H) composite, the maximum $\%$ age removal of $\mathrm{Cr}$ (III) was $84.83 \%$, while it was only $77.33 \%$ employing polyaniline (PANI). After the maximum removal of $\mathrm{Cr}$ (III), the adsorption rates decreased to a constant value with increase in contact time because of all the available active sites were covered..$^{2-5}$

Effect of $p H$

$\mathrm{pH}$ of the aqueous solution is clearly an important parameter that controls the biosorption process. The $\%$ age removal of $\mathrm{Cr}$ (III) was studied as a function of $\mathrm{pH}$ in the range of 1.0-7.0. Alkaline $\mathrm{pH}$ was avoided, because it results in the precipitation of $\mathrm{Cr}(\mathrm{OH})_{3}$. The results are shown in Fig. 6.

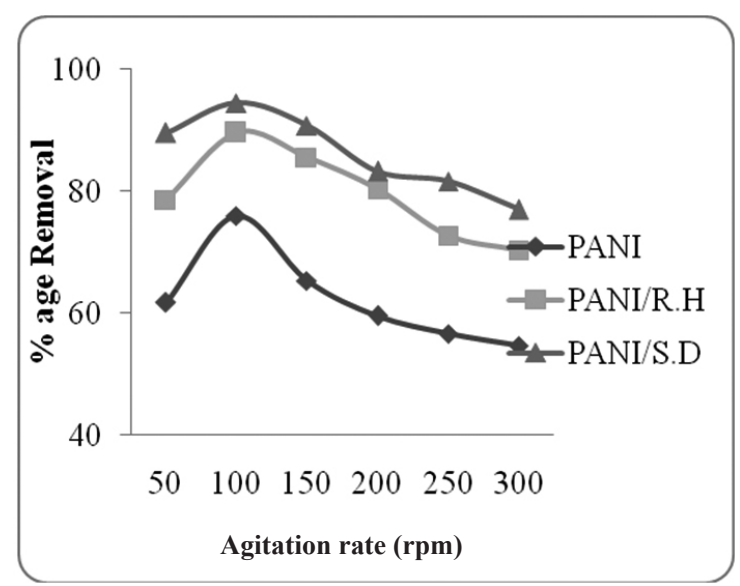

Fig. 6: Effect of $p H$ on \% age removal of $\mathrm{Cr}$ (III).

The maximum adsorption of $\mathrm{Cr}$ (III) was observed at $3.0 \mathrm{pH}$ using polyaniline and its composites. The maximum \% age removal value for polyaniline/saw dust (PANI/S.D) composite was $95.6 \%$. In case of polyaniline/rice husk (PANI/R.H) composite, the maximum \% age removal of Cr (III) was $86.35 \%$, whereas it was $77.26 \%$ when polyaniline (PANI) was employed. The $\mathrm{pH}$ dependency is basically related with the type and ionic state of functional groups present on the adsorbents and state of chromium in solution. The adsorption resulted due to the chelate type interactions between the positive chromium ions: $\mathrm{Cr}(\mathrm{OH})^{2+}, \mathrm{Cr}(\mathrm{OH})^{+}$and $\mathrm{Cr}$ (III) and , $-\mathrm{NH}$, $\mathrm{N}=\mathrm{Q}=\mathrm{N}$ and $\mathrm{N}=\mathrm{B}=\mathrm{N}$ functional groups in adsorbents. At $\mathrm{pH} 3.0$ or less, $\mathrm{Cr}$ (III) is a dominating specie but above that $\mathrm{pH}, \mathrm{Cr}$ (III) concentration gradually decreases while that of $\mathrm{Cr}(\mathrm{OH})^{2+}$ and $\mathrm{Cr}(\mathrm{OH})_{2}^{+}$increases. That's why, maximum removal of $\mathrm{Cr}$ (III) occurred at $\mathrm{pH} 3.0$. Above this $\mathrm{pH}$ value, there was a decline in adsorption because of reduction in the number of $\mathrm{Cr}$ (III) ions as they hydrolyzed to $\mathrm{Cr}(\mathrm{OH})^{2+}$ and $\mathrm{Cr}(\mathrm{OH})_{2}^{+}$. The presence of these chromic species with less charge resulted in decreased adsorption rates. ${ }^{8,14}$

\section{Effect of agitation speed}

The effect of variation in the agitation speed on the adsorption of $\mathrm{Cr}$ (III) was studied and the results are shown in Fig. 7. It was observed that $\%$ age removal of $\mathrm{Cr}$ (III) increased with the decrease in stirring speed. At $100 \mathrm{rpm}$ maximum adsorption occurred using all adsorbents. After that the kinetic energy of $\mathrm{Cr}$ (III) and adsorbent particles was increased to a level that they collide with each other with a greater speed resulting in detachment of loosely bound ions. Also they did not get appropriate time to interact with each other. The maximum \% age removal of $\mathrm{Cr}$ (III) was $94.45 \%$ using polyaniline/saw dust (PANI/S.D) composite, $89.53 \%$ employing polyaniline/rice husk (PANI/ R.H) composite and $75.96 \%$ in case of polyaniline (PANI).

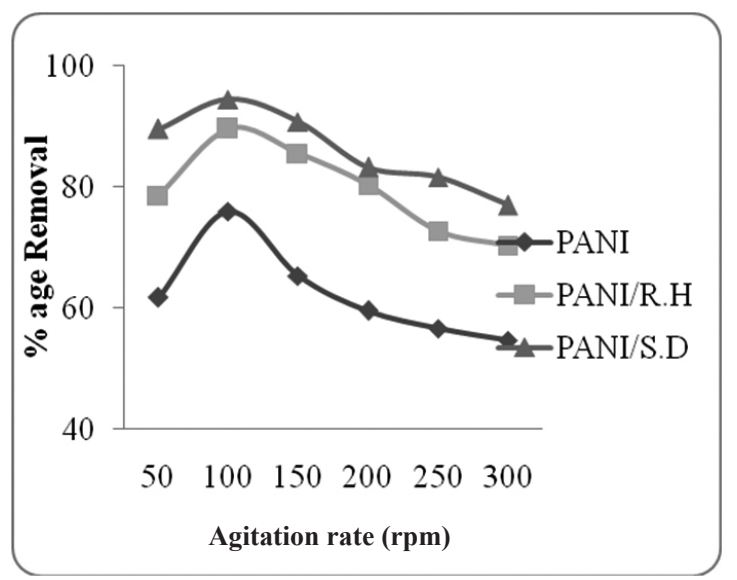

Fig. 7: Effect of agitation speed on \% age removal of $\mathrm{Cr}$ (III).

By increasing the speed, there was no further increase in adsorption. This is because all binding sites have been utilized and no binding sites were available for further adsorption. An increasing agitation rate may reduce the film boundary layer, surrounding the biosorbent particles, thus increasing the external film diffusion rate and the uptake rate. ${ }^{5,8}$

\section{Effect of temperature}

The adsorption of $\mathrm{Cr}$ (III) on polyaniline and its composites was studied at various temperatures ranging $10-80^{\circ} \mathrm{C}$. The results are given in Fig. 8. The maximum $\%$ age removal of $\mathrm{Cr}$ (III) occurred at $20{ }^{\circ} \mathrm{C}$ in case of polyaniline (PANI) and polyaniline/rice husk (PANI/R.H) composite, while at $30{ }^{\circ} \mathrm{C}$ in case of polyaniline/saw dust (PANI/S.D) composite. The \% age removal of $\mathrm{Cr}$ (III) values were $65.6,85.91$ and $97.5 \%$ for polyaniline (PANI), polyaniline/ rice husk (PANI/R.H) and polyaniline/saw dust (PANI/S.D) composites respectively. The decrease in adsorption might happened due to the fact that at high temperature molecules move with greater speed and less time of interaction was available for adsorbate with adsorbent active sites..$^{14,16}$

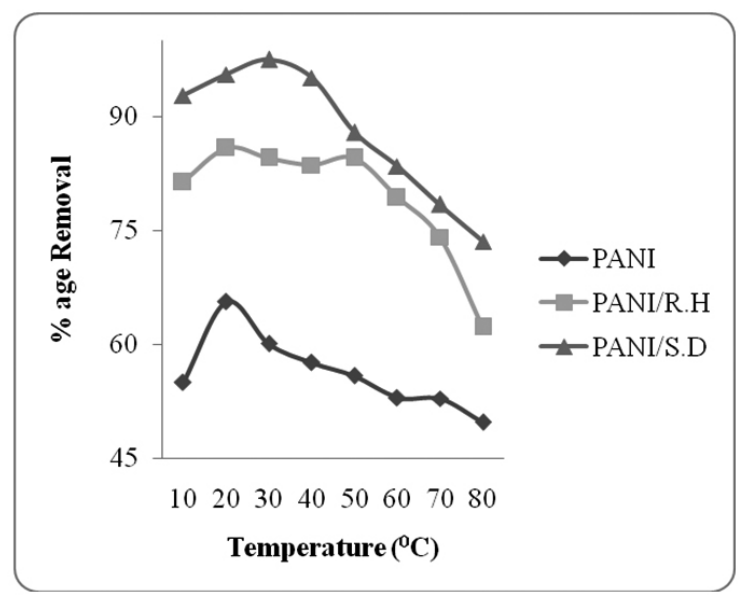

Fig. 8: Effect of temperature on \% age removal of $\mathrm{Cr}$ (III). 


\section{Adsorption isotherms}

The Langmuir and Freundlich isotherms for all adsorbents are shown in Figs. 9 and 10 respectively and the corresponding parameters are given in Table 2 .

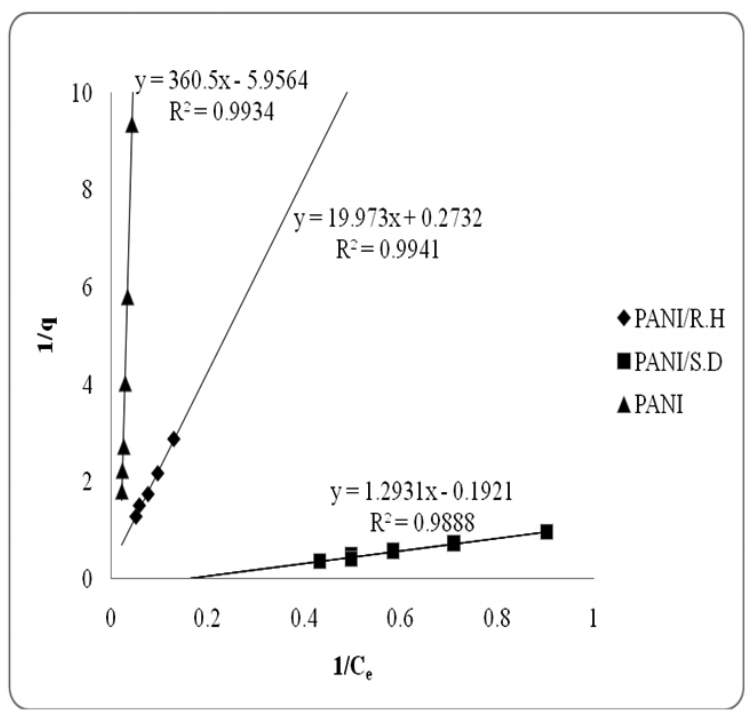

Fig. 9: Langmuir isotherms for adsorption of $\mathrm{Cr}$ (III).

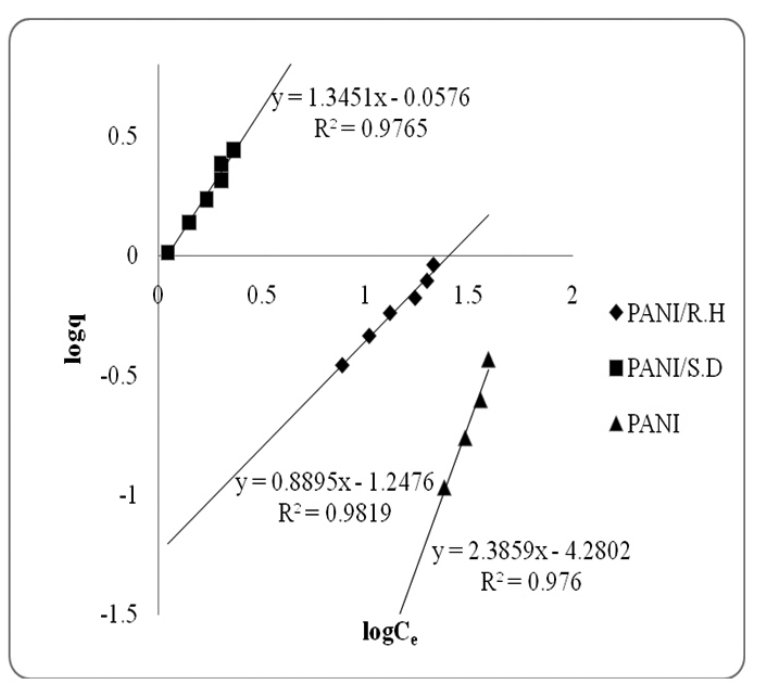

Fig.10: Freundlich isotherms for adsorption of $\mathrm{Cr}$ (III).

The correlation coefficients obtained from the linear plots of Freundlich isotherm model fitted better than Langmuir when isolated polyaniline (PANI) was used as an adsorbent (Table 3).

This value pointed out that the equilibrium data better fit to the Freundlich isotherm model. It referred to the multi layer physiosorption of $\mathrm{Cr}$ (III) on polyaniline (PANI). But in case of polyaniline composites, the correlation coefficient values clearly suggested that Langmuir isotherm model hold good for explaining adsorption of $\mathrm{Cr}$ (III) on these adsorbents. The data fitted indicated the homogeneous distribution of active sites on the composite surface, which results in chemisorption of $\mathrm{Cr}$ (III) on adsorbent. Because it is the basic assumption of Langmuir isotherm model that the adsorbent surface is homogeneous and monolayer chemisorption will occur. ${ }^{5}$
Table 3: Isothermal and thermodynamical parameters for adsorption of $\mathrm{Cr}(I I I)$.

\begin{tabular}{|c|c|c|c|c|c|c|c|}
\hline \multirow{2}{*}{$\begin{array}{l}\text { Adsor- } \\
\text { bent }\end{array}$} & \multicolumn{3}{|c|}{$\begin{array}{l}\text { Langmuir Isotherm } \\
\text { Parameters }\end{array}$} & \multicolumn{3}{|c|}{$\begin{array}{c}\text { Freundlich Isotherm } \\
\text { Parameters }\end{array}$} & \multirow{2}{*}{$\begin{array}{c}\text { Thermo- } \\
\text { dynami- } \\
\text { cal pa- } \\
\text { rameter } \\
\\
\Delta \mathbf{G}^{\mathrm{o}} \\
(\mathrm{KJ} / \mathrm{mol})\end{array}$} \\
\hline & $\mathbf{R}^{2}$ & $\begin{array}{c}\underset{(\mathbf{m} g}{\mathbf{q}_{\mathrm{m}}} \\
\left.\mathbf{g}^{-1}\right)\end{array}$ & $\begin{array}{c}\mathbf{b} \\
(\mathbf{L} \\
\left.\mathbf{g}^{-1}\right)\end{array}$ & $\mathbf{R}^{2}$ & $\mathbf{K}_{\mathrm{F}}$ & $1 / n$ & \\
\hline PANI & 0.988 & 0.165 & 0.016 & 0.989 & 0.0053 & 2.381 & -10.245 \\
\hline PANI/R.H & 0.990 & 4.739 & 0.010 & 0.982 & 0.057 & 0.888 & -11.410 \\
\hline PANI/S.D & 0.988 & 5.128 & 0.150 & 0.976 & 0.877 & 1.345 & -4.700 \\
\hline
\end{tabular}

' $q$ ' values were $0.165,4.739$ and $5.128 \mathrm{mg} \mathrm{g}^{-1}$ for polyaniline (PANI), polyaniline/rice husk (PANI/R.H) and polyaniline/saw dust (PANI/S.D) composites respectively. Comparison of adsorption capacity of PANI composites with previous adsorbents for adsorption of $\mathrm{Cr}$ (III) was shown in table 4. It shows that PANI composites show a good potential for adsorption of $\mathrm{Cr}$ (III) from waste water. Although, they are not effective like ion exchange resins, but they have the potency for treating waste water stream containing less Cr (III) ions. The constant ' $b$ ' is related with the affinity of the active binding sites. Its values were $0.016,0.010$ and $0.150 \mathrm{~L} \mathrm{~g}^{-1}$ for polyaniline (PANI), polyaniline/rice husk (PANI/R.H) and polyaniline/saw dust (PANI/ S.D) composites respectively. The increasing values of ' $b$ ' for the $\mathrm{Cr}$ (III) indicated the increase in adsorption at relatively higher temperatures. ' ${ }^{8} K_{F}$, is the binding constant which is related with the adsorption capacity of adsorbent. Its values were $0.0053,0.057$ and 0.877 for polyaniline (PANI), polyaniline/rice husk (PANI/R.H) composite and polyaniline/saw dust (PANI/ S.D) composite respectively. The term ' $1 / n$ ' is an empirical parameter that is related to adsorption intensity. Its value varies with heterogeneity and nature of the adsorbing surface. Its values were 2.381, 0.888 and 1.345 for isolated polyaniline (PANI), polyaniline/rice husk (PANI/R.H) and polyaniline/saw dust (PANI/S.D) composites respectively. ${ }^{5,8}$

Table 4: Comparison of adsorption capacity of PANI composites with previous adsorbents for adsorption of $\mathrm{Cr}(I I I){ }^{8}{ }^{8}$

\begin{tabular}{|c|c|}
\hline Adsorbents & $\mathbf{q}_{\mathbf{m}}(\mathbf{m g} / \mathbf{g})$ \\
\hline Brown coal & $0.1-0.3$ \\
\hline Saw dust & 3.61 \\
\hline Bagasse & 0.03 \\
\hline Waste tea & 1.55 \\
\hline PANI & 0.165 \\
\hline PANI/R.H & 4.739 \\
\hline PANI/S.D & 5.128 \\
\hline
\end{tabular}

\section{Sorption thermodynamic}

The Gibbs free energy of adsorption $\left(\Delta \mathrm{G}^{\circ}\right)$ of $\mathrm{Cr}$ (III) on all adsorbents was calculated from the Langmuir constant ' $\mathrm{b}$ ' and mentioned in Table 2. It was found to be $-10.245,-11.41$ and $-4.7 \mathrm{KJ} / \mathrm{mol}$ with polyaniline (PANI), polyaniline/rice husk (PANI/R.H) and polyaniline/saw dust (PANI/S.D) composites respectively. The negative value of $\Delta \mathrm{G}^{o}$ confirmed the feasibility and spontaneity of adsorption process with greater removal of $\mathrm{Cr}$ (III) with polyaniline and its composites. These values also indicated the fact that adsorption of $\mathrm{Cr}$ (III) using polyaniline/saw dust (PANI/S.D) composite was more favorable and spontaneous process as compared to other two adsorbents. ${ }^{18}$

\section{Mechanism discussion}

Fig. 11 shows the possible mechanism of $\mathrm{Cr}$ (III) adsorption on polyaniline/ rice husk (PANI/R.H) and polyaniline/saw dust (PANI/S.D) composites. In the Fig. 11, $\mathrm{A}^{-}$is anion doped in PANI/R.H and PANI/S.D during the chemical oxidation process of aniline. It is widely accepted that nitrogen-containing functional groups can act as adsorption sites for metal ions. Adsorption isotherms confirmed that the removal of $\mathrm{Cr}$ (III) occurs by chemisorption in monolayer fashion on the surfaces of polyaniline/rice husk (PANI/R.H) and polyaniline/saw dust (PANI/S.D) composites. 


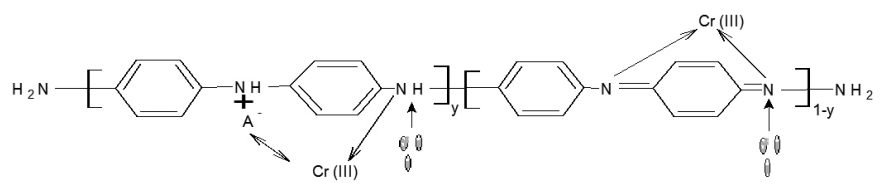

Fig.11: Mechanism for Cr (III) removal by polyaniline composites.

The overall adsorption of $\mathrm{Cr}$ (III) to the composite increased as compared to that on the simple polyaniline, because of the availability of more binding sites on the composites. ${ }^{16}$

Desorption studies

The regeneration of used adsorbents using different acids was quantified and the results are shown in Fig. 12.

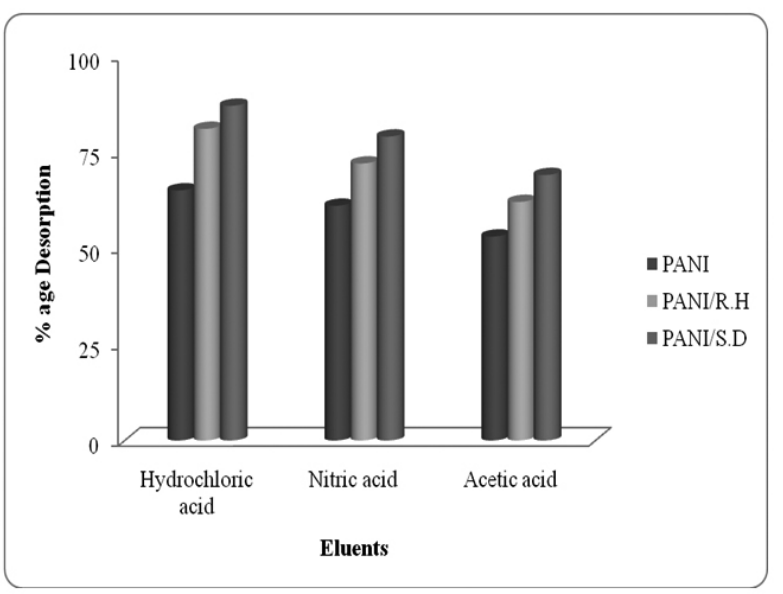

Fig. 12: Regeneration of adsorbents using different eluents.

It was found that as compared to other acids, $\mathrm{HCl}$ is a good eluent for desorption of $\mathrm{Cr}$ (III) from all adsorbents. The regenerated adsorbent can be re-employed for adsorption with a little decrease in efficiency

\section{Real industrial effluent treatment}

Various results obtained from previous optimization experiments were employed to conduct a batch experiment with real industrial effluents from industry near Lahore. There was slight decrease in percentage removal efficiency when the adsorbents were used for treatment of real industrial effluents. Using PANI, the maximum \% age removal of $\mathrm{Cr}$ (III) was $63.21 \%$ while in case of PANI/R.H and PANI/S.D, the removal efficiency was 72.31 and $81.43 \%$. Moderate to a slight decrease recorded in adsorption efficiency which could be because of the presence of various contaminants which may compete for binding sites on the adsorbents.

\section{CONCLUSION}

Two composites of polyaniline i.e. polyaniline/rice husk (PANI/R.H) and polyaniline/saw dust (PANI/S.D) were synthesized, characterized and employed as adsorbents for $\mathrm{Cr}$ (III). Composites of polyaniline with rice husk and saw dust played an important role in modifying the morphology and preventing the aggregation of the particles of polyaniline. At $100 \mathrm{rpm}$ agitation speed and at a $\mathrm{pH} 3.0$, the optimal $\mathrm{Cr}$ (III) removal was observed. The batch experiments showed that the adsorption isotherms $\mathrm{Cr}$ (III) were different, which suggested that physiosorption occurred using isolated polyaniline and chemisorption occurred when composites were employed for adsorption. The negative value of $\Delta \mathrm{G}^{\circ}$ confirmed the spontaneity and feasibility of the adsorption process. The adsorption efficiency of polyaniline/ saw dust composite was maximum as compared to simple polyaniline and its rice husk composite. The observed trend of adsorption for these adsorbents was decreased in the following order: PANI/S.D > PANI/R.H > PANI. For desorbing $\mathrm{Cr}$ (III) from adsorbents, $\mathrm{HCl}$ was found a good eluent. From this study, it can be safely concluded that polyaniline composites with rice husk and saw dust of Eucalyptus camaldulensis are good adsorbents for the removal of $\mathrm{Cr}$ (III) from aqueous media.

\section{REFERENCES}

1. J. L. G. Torresdey, K. J. Tiemann, V. Armendariz, J. Hazard. Mater. 80(13), 175 (2000).

2. J. Anwar, U. Shafique, M. Salman, W. Zaman, S. Anwar, J. M. Anzano, J. Hazard. Mater, 171, 797 (2009).

3. N. Ahalya, R. D. Kanamadi, T. V. Ramachandra, Electron. J. Biotechn. 8(3), 258 (2005).

4. H. Gao, Y. Liu, G. M. Zeng, W. H. Xu, T. Li, W. B. Xia, J. Hazard. Mater. 150(2), 446 (2008).

5. J. Anwar, U. Shafique, W. Zaman, M. Salman, Z. Hussain, M. Saleem, N. Shahid, S. Mahboob, S. Ghafoor, M. Akram, R. Rehman, N. Jamil, Green Chem. Lett. \& Revs. 3(3), 239 (2010).

6. R. Rehman, T. Mahmud, J. Anwar, M. Salman, U. Shafique, W. Zaman, F. Ali, J. Chem. Soc. Pak. 33(2), 228 (2011).

7. J. Rivera-Utrilla, M. Sanchez-Poloa, V. Gomez-Serranob, P. M. Alvarezc, M. C. M. Alvim-Ferrazd, J.M. Dias, J. Hazard. Mater. 187, 1(2011).

8. J. Anwar, U. Shafique, W. Zaman, Z. Nisa, M. A. Munawar, N. Jamil, M. Salman, A. Dar, R. Rehman, J. Saif, H. Gul, T. Iqbal, Int. J. Phytoremediat. 13(5), 410 (2011).

9. L. Aia, J. Jianga, R. Zhang, Synth. Met. 160, 762 (2010)

10. M. A. Salem, React. Funct. Polym. 70, 707 (2010).

11. Y. Zhang, Q. Li, L. Sun, R. Tang, J. Zhai, J. Hazard. Mater. 175, 404 (2010).

12. R. K. Gupta, R. A. Singh, S. S. Dubey, Sep. Purif. Technol. 38, 225 (2004).

13. M. S. Mansour, M. E. Ossman, H. A. Farag, Desalination. 272, 301 (2011).

14. P. A. Kumar, S. Chakraborty, M. Ray, Chem. Eng. J. 141, 130 (2008).

15. Q. Li, L. Sun, Y. Zhang, Y. Qian, J. Zhai, Desalination. 266, 188 (2011).

16. M. R. Samani, S. M. Borghei, A. Olad, M. J. Chaichi, J. Hazard. Mater. 184, 248 (2010).

17. F. Kanwal, S. A. Siddiqi, S. Tasleem, G. Sakina, T. Jamil, J. Chem. Soc. Pak. 31(6), 882 (2009).

18. N. A. Oladoja, I. O. Asia, C. O. Aboluwoye, Y. B. Oladimeji, Turkish J. Eng. Env. Sci. 32, 303 (2008). 